\title{
AÇAFRÃO EM PÓ (Curcuma longa L.) EM DIETAS DE FRANGOS DE CORTE
}

João Paulo Belém de Sousa, Mônica Maria de Almeida Brainer, Brena Cristine Rosário Silva, Paulo Ricardo de Sá da Costa Leite, Jean Martins de Souza, Thony Assis Carvalho, Ronaildo Fabino Neto, Vilson Matias Pinto

Instituto Federal Goiano - IFG, Campus Ceres. E-mail: monica.brainer@ifgoiano.edu.br

\section{RESUMO}

Objetivou-se avaliar os efeitos da inclusão de diferentes níveis de açafrão em pó (Curcuma longa L.) na ração de frangos de corte em comparação ao antibiótico promotor de crescimento. Foram utilizados 720 pintos de corte de 1 dia, da linhagem Cobb, distribuídos em delineamento inteiramente casualizado, em arranjo fatorial $5 \times 2$ (cinco tratamentos e dois sexos), com quatro repetições e 18 aves por unidade experimental. Os tratamentos foram: ração basal (RB) $+150 \mathrm{~g} / \mathrm{kg}$ de bacitracina de zinco, RB sem aditivos, $\mathrm{RB}+3,3 \mathrm{~g} / \mathrm{kg}$ de açafrão, RB $+6,6 \mathrm{~g} / \mathrm{kg}$ de açafrão e $\mathrm{RB}+10 \mathrm{~g} / \mathrm{kg}$ de açafrão. Avaliou-se o desempenho (peso vivo, consumo de ração, ganho de peso, conversão alimentar e mortalidade), rendimento de carcaça, peso relativo de vísceras e a rentabilidade econômica. Os dados obtidos foram submetidos à ANOVA e as médias dos tratamentos submetidas à análise de regressão e teste de Dunett a $5 \%$. As aves alimentadas com açafrão não apresentaram diferenças entre as variáveis de desempenho, rendimento de carcaça e peso relativo de vísceras, quando comparadas às aves suplementadas ou não com antibiótico. A inclusão de $3,3 \mathrm{~g} / \mathrm{kg}$ de açafrão apresentou índice de rentabilidade semelhante ao tratamento $\mathrm{RB}+150 \mathrm{~g} / \mathrm{kg}$ de bacitracina de zinco. Portanto, a suplementação de açafrão em pó na dieta de frangos de corte tem ação no desempenho produtivo, no rendimento de carcaça e de cortes nobres, peso relativo de vísceras e comprimento de intestinos das aves semelhante ao antibiótico promotor de crescimento, sendo o nível 3,3 $\mathrm{g} / \mathrm{kg}$ o que apresenta a melhor rentabilidade econômica.

Palavras-chave: aditivo fitogênico; Curcumina; promotor de crescimento; rendimento de carcaça; viabilidade econômica.

\section{TURMERIC POWDER (Curcuma longa L.) IN THE FEED OF BROILER}

\section{ABSTRACT}

This study aimed to evaluate the effects of inclusion of different levels of turmeric powder (Curcuma longa L.) in the feed of broilers. 720 Cobb broiler chicks of 1 day were used, distributed in a completely randomized design in a factorial arrangement $5 \times 2$ (five treatments and both sexes), with four replications and 18 birds per experimental unit. The treatments were: basal diet (BD) $+150 \mathrm{~g} / \mathrm{kg}$ of zinc bacitracin, BD without additives, $B D+3.3 \mathrm{~g} / \mathrm{kg}$ of turmeric, $\mathrm{BD}+6.6 \mathrm{~g} / \mathrm{kg}$ of turmeric and $\mathrm{BD}+10 \mathrm{~g} / \mathrm{kg}$ of turmeric. Were evaluated performance (live weight, feed intake, weight gain, feed conversion and mortality), carcass yield, viscera weight and economic profitability. The data were submitted to ANOVA and means of treatments submitted to regression analysis and test Dunett $5 \%$. Broilers fed with turmeric showed no differences between the performance variables, carcass yield and relative weight of viscera when compared to birds supplemented or not with antibiotics. Inclusion of $3.3 \mathrm{~g} / \mathrm{kg}$ of turmeric presented profitability index similar to the treatment RB $+150 \mathrm{~g} / \mathrm{kg}$ zinc bacitracin. Therefore, supplementation of turmeric powder in broiler diet has action on productive performance, carcass yield and the relative weight of viscera and length of the intestines of birds similar to the antibiotic growth promoter, and the level $3.3 \mathrm{~g} / \mathrm{kg}$ has the best economic returns.

Keywords: phytogenic additive; Curcumin; growth promoter; carcass yield; economic viability. 


\section{INTRODUÇÃO}

Os antibióticos em doses subterapêuticas são utilizados como promotores de crescimento para frangos de corte há mais de 50 anos. Atualmente, em todo o mundo, essa prática está enfrentando severas restrições, pois acredita-se que a administração contínua de antibióticos às dietas induz o desenvolvimento da resistência bacteriana aos compostos utilizados na terapêutica humana. Com a proibição do uso de antibióticos como promotores de crescimento em alguns países do mundo, torna-se imprescindível o uso de produtos alternativos com ação melhoradora de desempenho, evitando-se a polêmica sobre resistências bacterianas em humanos (SANTOS, 2010).

Dentre as alternativas, destaca-se o açafrão (Curcuma longa L.), também conhecido como cúrcuma ou açafrão da Índia, que é originário do sudeste asiático e pertence à família Zingiberaceae (VILELA; ARTUR, 2008). Por vezes é confundido no Brasil com outra espécie, Crocus sativus, também denominado açafrão, sendo este, no entanto, conhecido como açafrão verdadeiro (CECILIO FILHO et al., 2000).

Quanto à composição química, o açafrão é rico em curcumina ( 30 a $40 \mathrm{~g} / \mathrm{kg}$ ), um composto polifenoico responsável pela cor amarela característica. A curcumina possui ação hepatoprotetora, antioxidante, anti-inflamatória, antiparasitária e anticancerígena, além de apresentar baixa toxicidade (PINTÃO; SILVA, 2008).

Várias pesquisas comprovaram os efeitos benéficos da suplementação de açafrão sobre o desempenho de frangos de corte. Al-Sultan (2003) relatou que a adição de $5 \mathrm{~g} / \mathrm{kg}$ de açafrão na ração resultou em significativa melhoria no ganho de peso e conversão alimentar de frangos de corte. Kumari et al. (2007) observaram que a suplementação de $1 \mathrm{~g} / \mathrm{kg}$ de açafrão em pó melhorou o desempenho de frangos.

De acordo com Durrani et al. (2006) o custo dos alimentos, por $\mathrm{kg}$ de ganho de peso, mostrou-se altamente favorável quando se adicionou $5 \mathrm{~g} / \mathrm{kg}$ de açafrão na ração em comparação aos demais tratamentos $(0 ; 2,5$ e 10 $\mathrm{g} / \mathrm{kg}$ ). Dessa forma, esses autores verificaram a viabilidade econômica na utilização de açafrão (Curcuma longa L.) como antifúngico e antioxidante na concentração de $5 \mathrm{~g} / \mathrm{kg}$ na ração.

Objetivou-se avaliar o efeito da inclusão de diferentes níveis de açafrão (Curcuma longa L.) em pó em dietas de frangos de corte sobre o desempenho, rendimento de carcaça, peso relativo de vísceras e biometria intestinal, além da rentabilidade econômica desta inclusão como alternativa ao uso de antibióticos promotores de crescimento.

\section{MATERIAL E MÉTODOS}

Antes de sua execução, o projeto foi submetido à Comissão de Ética no Uso de Animais (CEUA) do Instituto Federal Goiano, sendo aprovado com o número de protocolo 002/2014, o que viabilizou sua implantação.

$\mathrm{O}$ experimento foi realizado no setor de avicultura do Instituto Federal Goiano Campus Ceres no período de fevereiro a abril de 2015. Foram alojados 720 frangos de corte da linhagem Cobb, com peso inicial de 44,39 $\pm 0,36 \mathrm{~g}$, distribuídos em delineamento experimental inteiramente casualizado, em arranjo fatorial $5 \times 2$ (cinco tratamentos e dois sexos), com quatro repetições e 18 aves por parcela. O arranjo fatorial teve como objetivo averiguar a possibilidade de interação entre os diferentes tratamentos e os dois sexos.

Os tratamentos consistiram em: ração basal (RB) $+150 \mathrm{~g} / \mathrm{kg}$ de bacitracina de zinco (controle positivo), RB sem aditivo (controle negativo), $R B+3,3 \mathrm{~g} / \mathrm{kg}$ de açafrão, $\mathrm{RB}+6,6 \mathrm{~g} / \mathrm{kg}$ de açafrão e $R B+10 \mathrm{~g} / \mathrm{kg}$ de açafrão.

As rações basais à base de milho e farelo de soja foram formuladas de acordo com as exigências preconizadas por Rostagno et al. (2011) (Tabela 1). 
Tabela 1 - Composição percentual e valores calculados das rações basais sem aditivos em cada fase de criação

\begin{tabular}{|c|c|c|c|c|}
\hline \multirow{2}{*}{ Ingrediente $(\mathrm{g} / \mathrm{kg})$} & \multicolumn{4}{|c|}{ Fases } \\
\hline & Pré-inicial & Inicial & Crescimento & Final \\
\hline Milho grão & 55,66 & 59,79 & 62,41 & 67,19 \\
\hline Farelo de soja $45 \%$ & 38,05 & 34,54 & 31,36 & 27,14 \\
\hline Óleo de soja & 2,00 & 1,96 & 2,95 & 2,77 \\
\hline Fosfato bicálcico & 1,91 & 1,50 & 1,26 & 1,05 \\
\hline Calcário & 0,80 & 0,83 & 0,78 & 0,71 \\
\hline Sal comum & 0,51 & 0,48 & 0,46 & 0,45 \\
\hline DL-Metionina & 0,36 & 0,30 & 0,26 & 0,25 \\
\hline L-Lisina HCL & 0,32 & 0,25 & 0,22 & 0,26 \\
\hline L-Treonina & 0,12 & 0,08 & 0,05 & 0,06 \\
\hline Premix vitamínico ${ }^{1}$ & 0,10 & 0,10 & 0,08 & 0,06 \\
\hline Cloreto de colina $70 \%$ & 0,06 & 0,06 & 0,06 & 0,06 \\
\hline Anticoccidiano $^{2}$ & 0,06 & 0,06 & 0,06 & 0,00 \\
\hline Premix mineral $^{3}$ & 0,05 & 0,05 & 0,05 & 0,05 \\
\hline Total & 100,00 & 100,00 & 100,00 & 100,00 \\
\hline \multicolumn{5}{|c|}{ Composição nutricional calculada } \\
\hline EM (Mcal/kg) & 2,95 & 3,00 & 3,10 & 3,15 \\
\hline Proteína bruta (\%) & 22,20 & 20,80 & 19,50 & 18,00 \\
\hline Lisina digestível (\%) & 1,33 & 1,19 & 1,09 & 1,02 \\
\hline Lisina total $(\%)$ & 1,44 & 1,29 & 1,19 & 1,11 \\
\hline Met. + Cist. digestível (\%) & 0,94 & 0,85 & 0,79 & 0,74 \\
\hline Met. + Cist. total (\%) & 1,04 & 0,93 & 0,87 & 0,81 \\
\hline Metionina digestível (\%) & 0,65 & 0,57 & 0,52 & 0,49 \\
\hline Metionina total (\%) & 0,67 & 0,60 & 0,55 & 0,51 \\
\hline Treonina digestível (\%) & 0,85 & 0,77 & 0,70 & 0,66 \\
\hline Treonina total (\%) & 0,98 & 0,88 & 0,81 & 0,76 \\
\hline Potássio (\%) & 0,86 & 0,81 & 0,75 & 0,69 \\
\hline Cálcio (\%) & 0,92 & 0,82 & 0,73 & 0,64 \\
\hline Cloro (\%) & 0,35 & 0,34 & 0,33 & 0,32 \\
\hline Sódio (\%) & 0,22 & 0,21 & 0,20 & 0,20 \\
\hline
\end{tabular}

${ }^{1}$ Níveis de garantia por kg do produto: Ácido fólico $(\mathrm{min}) 700 \mathrm{mg}$; Ácido patotênico (min) $8.000 \mathrm{mg}$; Biotina (min) 60 mg; Niacina (min) 30 g; Selênio (min) 400 mg; Vit. A (min) 8.000.000 UI; Vit. B1 (min) 3.000 mg; Vit. B12 (min) 10.000 mcg; Vit. B2 (min) 4.000 mg; Vit. B6 (min) 2.000 mg; Vit. D3 (min) 2.000 .000 Ul; Vit E (min) 15.000 UI; Vit. K3 (min) $2.000 \mathrm{mg}$.

${ }^{2}$ Anticoccidiano salininomicina

${ }^{3}$ Níveis de garantia por kg do produto: Zinco (min) 126 g; Cobre (min) 12,6 g; lodo (min) 2.520 mg; Ferro (min) 105 g; Manganês ( $\min ) 126$.

O açafrão foi colhido e processado no município de Mara Rosa/GO, e após o processamento, foram coletadas amostras para realização de análises bromatológicas. De acordo com a análise da composição com base na matéria seca, o açafrão em pó continha $8,13 \mathrm{~g} / \mathrm{kg}$ de proteína bruta; $9,96 \mathrm{~g} / \mathrm{kg}$ de extrato etéreo e $5,96 \mathrm{~g} / \mathrm{kg}$ de matéria mineral.

Os parâmetros de desempenho avaliados semanalmente foram peso médio vivo, ganho de peso, consumo de ração, conversão alimentar e mortalidade. $O$ peso médio vivo foi obtido pelo peso médio dos frangos antes do jejum, aos 42 dias de idade. $O$ ganho de peso foi obtido através da diferença entre o peso inicial e o peso final de cada período. $O$ consumo de ração foi calculado considerando-se a ração fornecida e as sobras nos comedouros em cada semana e a conversão alimentar obtida por meio da divisão do consumo de ração e do peso das aves semanalmente. A mortalidade foi calculada pela divisão das aves mortas na semana pela quantidade de aves em cada box.

A mensuração das relações corporais (peso dos órgãos em relação ao peso corporal) e do comprimento do intestino, assim como, a 
avaliação de rendimento de carcaça e de cortes nobres foram determinadas no 42 임 da criação com a retirada e identificação de quatro aves com o peso médio de cada unidade experimental, perfazendo um total de 80 aves. As aves identificadas foram pesadas individualmente e submetidas a jejum por 8 horas antes do abate.

As aves foram sacrificadas através de deslocamento cervical e depois sangradas e depenadas seguindo as normas do abate humanitário. Após o abate foi realizada a pesagem da carcaça eviscerada, dos cortes nobres, da gordura abdominal, do coração, fígado, moela limpa, proventrículo, pâncreas, intestinos e baço, além da medição do intestino de cada ave individualmente. $O$ cálculo da relação em percentual de cada órgão com o peso corporal foi realizado de acordo com a seguinte fórmula: Relação do Peso do Órgão = peso do órgão/peso vivo x 1000. A morfometria intestinal e o rendimento de carcaça foi determinada em relação ao peso do abate (peso vivo após jejum de 8 horas), e o rendimento de cortes nobres e o teor de gordura abdominal em relação ao peso da carcaça eviscerada

A rentabilidade econômica foi calculada de acordo com a metodologia descrita por Ramos et al. (2011), sendo:
- Renda bruta média (RBM) - valor em reais ( $R \$$ ) obtido em função do peso médio vivo (PMV) e do preço do frango (PF) em kg. RBM = PMV $\times$ PF.

- Custo médio de arraçoamento (CMA) custo total relativo ao consumo de ração (CR) em todas as fases de criação em função do custo da ração em cada fase de criação. $C M A=(C R$ em cada fase de criação $x$ custo ração).

- Margem bruta média (MBM) - diferença entre a renda bruta média (RBM) e os custos com alimentação. MBM = RBM CMA.

- Rentabilidade média (RM) - divisão entre a margem bruta média (MBM) e o custo médio de alimentação (CMA). RM = $\mathrm{MBM} / \mathrm{CMA} \times 100$.

- Índice relativo de rentabilidade (IRR) relação entre a rentabilidade média (RM) dos tratamentos e o controle. IRR = RM do tratamento testado/RM tratamento controle $x 100$.

Foi adotado o preço médio de comercialização do $\mathrm{kg}$ do frango vivo $(\mathrm{R} \$ 2,65)$ nos cálculos de rentabilidade. $O$ custo médio das rações experimentais $(\mathrm{kg})$ foi calculado a partir dos preços das matérias-primas utilizadas no preparo das rações (Tabela 2).

Tabela 2. Preço dos ingredientes e custo médio das rações utilizadas no experimento

\begin{tabular}{lc}
\hline \multicolumn{1}{c}{ Ingredientes } & $\mathrm{R} \$ / \mathrm{kg}$ \\
\hline Milho & 0,49 \\
Farelo de soja & 1,32 \\
Fosfato bicálcico & 2,50 \\
Óleo & 2,50 \\
Metionina & 55,00 \\
Lisina & 14,95 \\
Treonina & 10,50 \\
Premix mineral & 11,50 \\
Premix vitamínico & 16,63 \\
Anticoccidiano & 15,64 \\
Cloreto de colina & 9,16 \\
Bacitracina de zinco & 17,60 \\
Sal & 1,50 \\
Calcário & 0,24 \\
Açafrão & 4,50 \\
\hline \multicolumn{1}{c}{ Rações Experimentais } & $\mathrm{R} \$ / \mathrm{kg}$ \\
\hline Ração basal (RB) + 150 g/kg de bacitracina de zinco & 1,09 \\
RB sem aditivos & 1,07 \\
RB + 3,3 g/kg de açafrão & 1,10 \\
RB + 6,6 g/kg de açafrão & 1,12 \\
RB + 10 g/kg de açafrão & 1,14 \\
\hline
\end{tabular}


As médias de temperatura máxima $\mathrm{e}$ mínima no período experimental foram 30,2 ํ $\mathrm{C}$ 24,5으, respectivamente. $E$ as médias de umidade relativa do ar máxima e mínima foram $82,6 \%$ e $77,3 \%$, respectivamente.

Os dados dos tratamentos quantitativos (níveis de inclusão do açafrão) foram submetidos à análise de variância e regressão polinomial a 5\% de probabilidade. As médias do tratamento RB + $150 \mathrm{~g} / \mathrm{kg}$ de bacitracina de zinco (controle positivo) foram comparadas aos demais tratamentos através do teste de Dunnett ao nível de $5 \%$ de probabilidade. Para as análises estatísticas foi utilizado o programa Assistat (Silva, 2016).

\section{RESULTADOS E DISCUSSÃO}

De acordo com a análise de regressão das variáveis de desempenho em função dos diferentes níveis de açafrão na dieta de ambos os sexos, não foram verificadas diferenças estatísticas entre os tratamentos, com exceção da conversão alimentar, que apresentou um efeito cúbico (Tabela 3).

Tabela 3. Médias de peso vivo (PV), consumo de ração (CR), ganho de peso (GP) conversão alimentar (CA) e mortalidade (MORT) de frangos de corte machos e fêmeas da linhagem Cobb suplementados ou não com diferentes níveis de açafrão no período de 1 a 42 dias de vida\#

\begin{tabular}{|c|c|c|c|c|c|}
\hline \multirow{2}{*}{ Tratamentos } & PV & CR & GP & \multirow{2}{*}{$\begin{array}{c}\mathrm{CA}^{2} \\
\mathrm{~kg} / \mathrm{kg}\end{array}$} & \multirow{2}{*}{$\begin{array}{c}\text { MORT } \\
\%\end{array}$} \\
\hline & \multicolumn{3}{|c|}{$\mathrm{kg}$} & & \\
\hline Controle positivo $^{1}$ & 2,63 & 4,40 & 2,58 & 1,71 & $1,03^{a}$ \\
\hline 0,0 g/kg de açafrão & 2,58 & 4,33 & 2,54 & 1,71 & $0,60^{b}$ \\
\hline 3,3 g/kg de açafrão & 2,62 & 4,42 & 2,58 & 1,72 & $2,08^{b}$ \\
\hline 6,6 g/kg de açafrão & 2,59 & 4,43 & 2,54 & 1,75 & $0,60^{b}$ \\
\hline $10 \mathrm{~g} / \mathrm{kg}$ de açafrão & 2,62 & 4,37 & 2,57 & 1,70 & $0,00^{b}$ \\
\hline CV (\%) & 2,78 & 2,77 & 2,82 & 2,09 & 2,73 \\
\hline \multicolumn{6}{|c|}{ Sexo } \\
\hline Fêmeas & $2,38^{A}$ & $4,06^{B}$ & $2,33^{B}$ & $1,74^{\mathrm{A}}$ & $0,94^{B}$ \\
\hline Machos & $2,83^{\mathrm{B}}$ & $4,72^{A}$ & $2,79^{A}$ & $1,69^{\mathrm{B}}$ & $2,04^{A}$ \\
\hline \multicolumn{6}{|c|}{ Valor de $\mathrm{P}$} \\
\hline Tratamentos & 0,5742 & 0,4595 & 0,5686 & 0,1012 & 0,0001 \\
\hline Sexos & 0,0001 & 0,0001 & 0,0001 & 0,0004 & 0,0001 \\
\hline Trat. $x$ Sex. & 0,6542 & 0,8561 & 0,6515 & 0,1910 & 0,0001 \\
\hline
\end{tabular}

${ }^{1} \mathrm{RB}+150 \mathrm{~g} / \mathrm{kg}$ de bacitracina de zinco

${ }^{2} y=1,708-0,117 x-0,573 x^{2}-0,462 x^{3}, R^{2}=0,99$.

CV - Coeficiente de variação.

${ }^{a, b}$ Médias seguidas de letras diferentes, na mesma coluna, diferem pelo teste de Dunnett $(P>0,05)$.

${ }_{A, B}$ Médias seguidas de letras diferentes, na mesma coluna, diferem pelo teste de Tukey $(P>0,05)$.

\# Teste de Dunnett - controle positivo e níveis de açafrão; Regressão Polinomial - níveis de açafrão.

Não houve interação entre os tratamentos e os dois sexos. Os machos apresentaram melhor desempenho que as fêmeas independentemente do tratamento. Comparando-se o desempenho dos frangos alimentados com os diferentes níveis de açafrão com 0 dos frangos suplementados com antibiótico promotor de crescimento na ração através do teste de média de Dunnett, também não foram observadas diferenças entre as variáveis no período experimental, com exceção do índice de mortalidade.

Entretanto, diferentes trabalhos, tais como os de Al-Sultan (2003), Durrani et al. (2006) e Mondal et al. (2015) relatam que o uso de cúrcuma como aditivo ao nível de $5 \mathrm{~g} / \mathrm{kg}$ melhora o desempenho global de frangos de corte. Segundo Nouzarian et al. (2011), a melhora do desempenho de frangos de corte suplementados com açafrão, pode estar relacionado com a utilização mais eficiente dos nutrientes, além do fato de o açafrão apresentar elevado potencial para inibir determinadas bactérias patogênicas. De acordo com os autores, o açafrão tem um efeito antioxidante e promotor de crescimento, com ação na redução do consumo e aumento do ganho de peso, entretanto neste trabalho esse efeito não foi observado até o nível de $1 \mathrm{~g} / \mathrm{kg}$ de inclusão na ração. 
Samarasingue et al. (2003) compararam o efeito da virginiamicina, mananoligossacarídeos (MOS) e açafrão em pó na dieta de frangos de corte e verificaram que o MOS e o açafrão apresentaram o mesmo efeito antimicrobiano a nível intestinal que a virginiamicina. Abbas et al. (2010) verificaram que a inclusão do açafrão na ração de frangos de corte nos níveis de 1 a $2 \mathrm{~g} / \mathrm{kg}$ não proporcionou melhorias no ganho de peso das aves, porém foi observado um maior ganho de peso nas aves que foram suplementadas com $3 \mathrm{~g} / \mathrm{kg}$ de açafrão na dieta. Os autores observaram que, neste nível, o açafrão apresentou uma ação anticoccidiana, refletindo no melhor desempenho.
Quanto aos resultados relativos ao rendimento de carcaça e rendimento de cortes nobres, não foram observados efeitos dos diferentes níveis de açafrão sobre as variáveis, com exceção para os rendimentos de coxa e sobrecoxa que apresentaram um efeito cúbico na equação de regressão (Tabela 4). Do mesmo modo, comparando-se as aves alimentadas ou não com o açafrão com as suplementadas com antibiótico promotor de crescimento, não foram verificadas diferenças no rendimento de carcaça e de cortes nobres.

Tabela 4. Rendimento de carcaça e de cortes nobres de frangos de corte machos e fêmeas alimentados com ou sem açafrão no período de 1 a 42 dias de vida

\begin{tabular}{|c|c|c|c|c|c|c|}
\hline \multirow{2}{*}{ Tratamento } & \multicolumn{6}{|c|}{ Variáveis } \\
\hline & Carcaça & Asa & Coxa da asa & Coxa $^{2}$ & Sobrecoxa ${ }^{3}$ & Peito \\
\hline Controle positivo $^{1}$ & 77,35 & 2,36 & 2,47 & 6,21 & 8,29 & 33,85 \\
\hline $0,0 \mathrm{~g} / \mathrm{kg}$ de açafrão & 77,79 & 2,31 & 2,50 & 6,32 & 8,49 & 33,76 \\
\hline $3,3 \mathrm{~g} / \mathrm{kg}$ de açafrão & 78,14 & 2,33 & 2,44 & 6,10 & 7,97 & 35,33 \\
\hline 6,6 g/kg de açafrão & 77,04 & 2,37 & 2,50 & 6,37 & 8,66 & 34,36 \\
\hline $10 \mathrm{~g} / \mathrm{kg}$ de açafrão & 77,36 & 2,35 & 2,52 & 6,16 & 8,31 & 34,73 \\
\hline \multirow[t]{2}{*}{ CV (\%) } & 1,76 & 4,11 & 5,97 & 4,49 & 6,28 & 3,90 \\
\hline & \multicolumn{5}{|c|}{ Sexo } & \\
\hline Fêmea & 77,57 & 2,33 & $2,42 b$ & $6,09 \mathrm{~b}$ & 8,30 & 34,61 \\
\hline \multirow[t]{2}{*}{ Macho } & 77,50 & 2,35 & $2,56 \mathrm{a}$ & $6,36 \mathrm{a}$ & 8,39 & 34,20 \\
\hline & \multicolumn{5}{|c|}{ Valor de P } & \\
\hline Tratamentos & 0,5388 & 0,7385 & 0,7888 & 0,3188 & 0,2394 & 0,1403 \\
\hline Sexo & 0,8844 & 0,2438 & 0,0155 & 0,0028 & 0,6344 & 0,3513 \\
\hline Trat. $x$ Sex. & 0,7697 & 0,2168 & 0,6069 & 0,0734 & 0,7849 & 0,6037 \\
\hline
\end{tabular}

${ }^{1} \mathrm{RB}+150 \mathrm{~g} / \mathrm{kg}$ de bacitracina de zinco.

${ }^{2} y=3,317-2,342 x+6,520 x^{2}-4,331 x^{3}, R^{2}=0,99$.

${ }^{3} y=8,488-5,639 x+15,673 x^{2}-10,217 x^{3}, R^{2}=0,99$.

CV - Coeficiente de variação.

a,b Médias seguidas de letras diferentes, na mesma coluna, diferem pelo teste de Tukey $(P>0,05)$.

\# Teste de Dunnett - controle positivo e níveis de açafrão; Regressão Polinomial - níveis de açafrão

Para estas variáveis também não houve interação entre os tratamentos e os sexos, sendo que os frangos machos tiveram um rendimento de coxa da asa e de coxa superior ao das fêmeas independentemente do tratamento a que foram submetidos.

Estes resultados estão de acordo com os encontrados por Mehala e Moorthy (2008) e Nouzarian et al. (2011). Esses autores não verificaram resultados significativos para 0 rendimento de carcaça ao avaliarem a inclusão de açafrão na dieta de frangos de corte. Por outro lado, Durrani et al. (2006) obtiveram um maior rendimento de carcaça, de peito e de coxa de frangos de corte alimentados com $5 \mathrm{~g} / \mathrm{kg}$ de açafrão na dieta.

Nas condições do presente estudo, os efeitos antioxidante e antimicrobiano do açafrão não refletiram no desempenho e no rendimento de carcaça das aves, do mesmo modo que o tratamento $\mathrm{RB}+150 \mathrm{~g} / \mathrm{kg}$ de bacitracina de zinco (controle positivo). Provavelmente, as condições locais de manejo e sanidade não tenham sido suficientes para provocar um desafio sanitário capaz de expor as aves a um estado de susceptibilidade e consequente prejuízo ao desempenho. Neste caso, o nível máximo de 10 $\mathrm{g} / \mathrm{kg}$ de inclusão nas dietas pode não ter sido 
suficiente para que o açafrão apresentasse ação antimicrobiana, antioxidante ou anticoccidiana nas aves suplementadas. Portanto, são necessários estudos sobre as condições ambientais e o modo de ação do açafrão sobre o metabolismo das aves.

Na Tabela 5 encontram-se os resultados referentes ao peso relativo de vísceras e gordura abdominal dos frangos machos e fêmeas submetidos aos diferentes tratamentos. Para estas variáveis também não houve interação entre os tratamentos e os sexos.
O peso relativo da moela apresentou um efeito cúbico na equação de regressão em função dos diferentes níveis de açafrão, e os pesos relativos de pâncreas e de gordura abdominal, um efeito linear. Neste caso, foi verificado que houve aumento do peso do pâncreas dos frangos com o aumento do nível de açafrão na ração, enquanto que a gordura abdominal teve um comportamento contrário. $\mathrm{O}$ aumento dos níveis de açafrão na ração dos frangos provocou um efeito linear na redução do teor de gordura abdominal dos frangos.

Tabela 5. Peso relativo de vísceras e gordura abdominal de frangos de corte machos e fêmeas alimentados com ou sem açafrão no período de 1 a 42 dias de vida\#

\begin{tabular}{|c|c|c|c|c|c|c|}
\hline \multirow{2}{*}{ Tratamento } & \multicolumn{6}{|c|}{ Variáveis } \\
\hline & Baço & Coração & Fígado & Pâncreas ${ }^{2}$ & Moela $^{3}$ & Gordura $^{4}$ \\
\hline Controle positivo $^{1}$ & 0,13 & 0,58 & 2,34 & 0,25 & 1,58 & 2,02 \\
\hline $0,0 \mathrm{~g} / \mathrm{kg}$ de açafrão & 0,11 & 0,60 & 2,32 & 0,22 & 1,55 & 2,31 \\
\hline 3,3 g/kg de açafrão & 0,11 & 0,55 & 2,30 & 0,22 & 1,47 & 2,12 \\
\hline 6,6 g/kg de açafrão & 0,13 & 0,57 & 2,37 & 0,25 & 1,69 & 1,80 \\
\hline $10 \mathrm{~g} / \mathrm{kg}$ de açafrão & 0,11 & 0,56 & 2,24 & 0,24 & 1,54 & 1,84 \\
\hline \multirow[t]{2}{*}{ CV (\%) } & 18,18 & 10,01 & 10,62 & 10,92 & 9,97 & 23,17 \\
\hline & \multicolumn{5}{|c|}{ Sexo } & \\
\hline Fêmea & 0,12 & 0,56 & 2,31 & $0,25 \mathrm{a}$ & 1,62 & 2,17 \\
\hline \multirow[t]{2}{*}{ Macho } & 0,11 & 0,58 & 2,31 & $0,22 b$ & 1,52 & 1,87 \\
\hline & \multicolumn{5}{|c|}{ Valor de P } & \\
\hline Tratamentos & 0,1712 & 0,5445 & 0,8528 & 0,2909 & 0,1134 & 0,2048 \\
\hline Sexos & 0,0606 & 0,0921 & 0,9859 & 0,0267 & 0,0687 & 0,0616 \\
\hline Trat. $x$ Sex. & 0,6771 & 0,7150 & 0,4593 & 0,8301 & 0,0987 & 0,5067 \\
\hline
\end{tabular}

${ }^{1} \mathrm{RB}+150 \mathrm{~g} / \mathrm{kg}$ de bacitracina de zinco.

${ }^{2} y=0,220+0,025 x, R^{2}=0,58$.

${ }^{3} y=1,552-1,341 x+4,315 x^{2}-2,976 x^{3}, R^{2}=0,99$.

${ }^{4} y=2,279-0,514 x, R^{2}=0,85$.

CV - Coeficiente de variação

a,b Médias seguidas de letras diferentes, na mesma coluna, diferem pelo teste de Tukey $(P>0,05)$.

\# Teste de Dunnett - controle positivo e níveis de açafrão; Regressão Polinomial - níveis de açafrão

Resultados semelhantes foram encontrados por Mondal et al. (2015), que avaliaram o efeito da inclusão de 5, 10 e $15 \mathrm{~g} / \mathrm{kg}$ de açafrão em pó sobre o peso absoluto do coração, fígado, moela e gordura abdominal. Os pesos do coração, fígado e moela não foram alterados pelos níveis de inclusão de açafrão, entretanto o peso absoluto da gordura abdominal diminuiu à medida que o nível de inclusão de açafrão aumentou.

De acordo com Wang et al. (2015) a deposição de gordura na região abdominal em frangos de corte é considerada um resíduo na avicultura, uma vez que representa uma perda no mercado por reduzir a aceitabilidade do consumidor. Os resultados obtidos em seus estudos indicaram que a suplementação de açafrão em pó na ração de frangos de corte apresenta potencial para reduzir o conteúdo de gordura abdominal. Essa diminuição da gordura abdominal se deve à influência da curcumina na apoptose dos adipócitos, ou mesmo na retirada da glicose sanguínea circulante (SUGIHARTO et al., 2011).

Entretanto, ao compararmos as aves alimentadas com diferentes níveis açafrão com as aves suplementadas com antibiótico promotor de crescimento, não foram verificadas diferenças no 
peso de vísceras e na gordura abdominal. Resultados semelhantes foram encontrados por Al-Sultan (2003) ao avaliarem o efeito da inclusão de 2,5; 5 e $10 \mathrm{~g} / \mathrm{kg}$ de açafrão em pó sobre o peso absoluto de fígado e baço.

Emadi e Kermanshahi (2006) verificaram que o peso de baço, fígado e pâncreas não foi afetado pela adição de 2,5; 5 e 7,5 g/kg açafrão em pó. Entretanto, foi observado que o peso do coração reduziu de acordo com o aumento do nível de inclusão de açafrão na dieta.

Entretanto, Nouzarian et al. (2011) encontraram diferenças estatísticas para peso relativo do fígado, sendo que as aves alimentadas com açafrão em pó $(3,3 ; 6,6$ e $10 \mathrm{~g} / \mathrm{kg})$ apresentaram menor peso de fígado em comparação com o tratamento controle, porém o peso relativo do baço, coração e pâncreas não apresentaram diferenças.

Segundo Dono (2013) o açafrão contém compostos ativos que estimulam a secreção e o fluxo biliar, que podem promover um estado de saúde do fígado. Também tem sido relatada a capacidade da curcumina de aumentar a concentração de catalase (REDDY; LOKESH, 1994), bem como a expressão de superóxido dismutase hepática (CHENG et al., 2005) e da glutationa peroxidase (YARRU et al., 2009). Essas enzimas possuem uma estreita relação com a capacidade antioxidante do corpo.

Foram observados efeitos dos tratamentos sobre $o$ peso relativo do proventrículo e de intestino, porém o comprimento dos intestinos não foi influenciado pelos diferentes níveis de açafrão na ração. 0 peso relativo do intestino apresentou um efeito cúbico na equação de regressão em função dos diferentes níveis de açafrão. Porém, o peso relativo de proventrículo apresentou um efeito linear, com redução do peso do órgão à medida que aumentou o nível de inclusão de açafrão na ração (Tabela 6).

Tabela 6 - Médias de peso relativo do proventrículo, peso relativo dos intestinos e comprimento dos intestinos de frangos de corte machos e fêmeas alimentados com ou sem açafrão no período de 1 a 42 dias de vida ${ }^{\#}$

\begin{tabular}{|c|c|c|c|}
\hline \multirow{2}{*}{ Tratamentos } & \multicolumn{3}{|c|}{ Variáveis } \\
\hline & Proventrículo $^{2}$ & Intestinos ${ }^{3}$ & Intestino $(\mathrm{m})$ \\
\hline Controle positivo $^{1}$ & 0,40 & $3,58 \mathrm{a}$ & 2,19 \\
\hline 0,0 g/kg de açafrão & 0,44 & 3,71 a & 2,16 \\
\hline 3,3 g/kg de açafrão & 0,41 & 3,56 a & 2,17 \\
\hline 6,6 g/kg de açafrão & 0,40 & $3,96 \mathrm{~b}$ & 2,19 \\
\hline 10 g/kg de açafrão & 0,38 & $3,72 \mathrm{a}$ & 2,16 \\
\hline CV (\%) & 10,04 & 6,36 & 4,79 \\
\hline \multicolumn{4}{|c|}{ Sexos } \\
\hline Fêmea & 0,42 & $3,80 \mathrm{~A}$ & $2,10 \mathrm{~B}$ \\
\hline Macho & 0,39 & $3,61 \mathrm{~B}$ & $2,24 \mathrm{~A}$ \\
\hline \multicolumn{4}{|c|}{ Valor de $\mathrm{P}$} \\
\hline Tratamentos & 0,1759 & 0,0163 & 0,9679 \\
\hline Sexos & 0,0211 & 0,0147 & 0,0001 \\
\hline Trat. $x$ Sex. & 0,3689 & 0,4574 & 0,7903 \\
\hline
\end{tabular}

${ }^{1} \mathrm{RB}+150 \mathrm{~g} / \mathrm{kg}$ de bacitracina de zinco.

${ }^{2} y=0,434-0,052 x, R^{2}=0,96$.

${ }^{3} y=3,713-2,426 x+7,738 x^{2}-5,302 x^{3}, R^{2}=0,99$.

CV - Coeficiente de variação.

a,b Médias seguidas de letras diferentes, na mesma coluna, diferem pelo teste de Dunnett $(P>0,05)$.

A,B Médias seguidas de letras diferentes, na mesma coluna, diferem pelo teste de Tukey $(P>0,05)$.

\# Teste de Dunnett - controle positivo e níveis de açafrão; Regressão Polinomial - níveis de açafrão

Entretanto, resultados diferentes aos encontrados no presente estudo foram relatados por alguns pesquisadores. Abou-Elkhair et al. (2014) verificaram que frangos alimentados com $5 \mathrm{~g} / \mathrm{kg}$ de açafrão apresentaram maior peso relativo de proventrículo, em comparação com o tratamento controle (ração basal sem aditivos). Do mesmo modo, Hussein (2013) verificou que a inclusão de $7 \mathrm{~g} / \mathrm{kg}$ aumentou o peso relativo do proventrículo. Enquanto que, Sadeghi et al. 
(2012) observaram que a infusão de $5 \mathrm{~g} / \mathrm{L}$ de açafrão não influenciou o peso relativo do proventrículo, porém o peso relativo do intestino aumentou significativamente em comparação com o tratamento controle.

Comparando-se as aves alimentadas com diferentes níveis de açafrão com as aves alimentadas com antibiótico promotor de crescimento, não foram verificadas diferenças do peso relativo do proventrículo e comprimento dos intestinos, entretanto o peso do intestino das aves suplementadas com $6,6 \mathrm{~g} / \mathrm{kg}$ de açafrão foi significativamente maior que as aves que receberam antibiótico na dieta. $\mathrm{Na}$ análise dessas variáveis também não houve interação entre os tratamentos e os sexos.

Através dos cálculos dos fatores renda bruta média, custo médio de arraçoamento, margem bruta média e rentabilidade média de cada tratamento foi estimado o índice relativo de rentabilidade da inclusão de diferentes níveis de açafrão na dieta de frangos de corte no período de 1 a 42 dias (Tabela 7).

Tabela 7. Valores de peso vivo ao abate (PV), renda bruta média (RBM), custo médio de arraçoamento (CMA), margem bruta média (MBM), rentabilidade média (RM) e índice relativo de rentabilidade (IRR) dos diferentes níveis de açafrão na dieta de frangos de corte no período de 1 a 42 dias de vida

\begin{tabular}{lcccccc}
\hline & PV $(\mathrm{kg})$ & RBM & CMA & MBM & RM & IRR $^{2}$ \\
\hline Controle Positivo $^{1}$ & 2,63 & 6,96 & $4,80 \mathrm{a}$ & $2,16 \mathrm{a}$ & $45,11 \mathrm{a}$ & $100,00 \mathrm{a}$ \\
\hline $0,0 \mathrm{~g} / \mathrm{kg}$ de açafrão & 2,58 & 6,83 & $4,63 \mathrm{~b}$ & $2,21 \mathrm{a}$ & $47,61 \mathrm{a}$ & $105,55 \mathrm{a}$ \\
$3,3 \mathrm{~g} / \mathrm{kg}$ de açafrão & 2,62 & 6,95 & $4,86 \mathrm{a}$ & $2,09 \mathrm{a}$ & $42,96 \mathrm{~b}$ & $98,23 \mathrm{a}$ \\
$6,6 \mathrm{~g} / \mathrm{kg}$ de açafrão & 2,59 & 6,85 & $4,96 \mathrm{a}$ & $1,89 \mathrm{~b}$ & $37,89 \mathrm{~b}$ & $83,08 \mathrm{~b}$ \\
$10 \mathrm{~g} / \mathrm{kg}$ de açafrão & 2,62 & 6,93 & $4,98 \mathrm{a}$ & $1,95 \mathrm{~b}$ & $38,99 \mathrm{~b}$ & $88,37 \mathrm{~b}$ \\
\hline $\mathrm{CV}(\%)$ & 2,78 & 2,78 & 2,78 & 6,38 & 7,06 & 6,26 \\
\hline \multicolumn{7}{c}{ Sexos } \\
\hline Fêmeas & $2,38 \mathrm{~b}$ & $6,31 \mathrm{~b}$ & $4,48 \mathrm{~b}$ & $1,81 \mathrm{~b}$ & $40,92 \mathrm{~b}$ & $90,74 \mathrm{~b}$ \\
Machos & $2,83 \mathrm{a}$ & $7,51 \mathrm{a}$ & $5,21 \mathrm{a}$ & $2,29 \mathrm{a}$ & $44,10 \mathrm{a}$ & $98,16 \mathrm{a}$ \\
\hline \multicolumn{7}{c}{$\mathrm{P}$ valor } \\
\hline Tratamentos & 0,5742 & 0,5742 & 0,0001 & 0,0001 & 0,0001 & 0,0001 \\
Sexos & 0,0001 & 0,0001 & 0,0001 & 0,0001 & 0,0022 & 0,0003 \\
Trat. $x$ Sex. & 0,6542 & 0,6542 & 0,9592 & 0,2919 & 0,2351 & 0,2412 \\
\hline
\end{tabular}

${ }^{1} \mathrm{RB}+150 \mathrm{~g} / \mathrm{kg}$ de bacitracina de zinco.

${ }^{2} y=28584 x^{2}-4837 x+106,7, R^{2}=0,86$

$\mathrm{CV}$ - Coeficiente de variação.

Para o cálculo do índice relativo de rentabilidade foi tomado como referência o tratamento $\mathrm{RB}+150 \mathrm{~g} / \mathrm{kg}$ de bacitracina de zinco (controle positivo) por ser a dieta padrão na criação de frangos de corte comercial.

Através da comparação dos índices relativos de rentabilidade da adição de diferentes níveis de açafrão com a ração controle positivo foi verificado que os maiores níveis de inclusão (6,6 e $10 \mathrm{~g} / \mathrm{kg}$ de açafrão) apresentaram os piores índices, enquanto que a inclusão de $3,3 \mathrm{~g} / \mathrm{kg}$ de açafrão teve uma rentabilidade semelhante à dieta padrão (tratamento controle positivo).
Não houve interação entre os fatores tratamentos e sexos, sendo os índices relativos de rentabilidade dos machos superiores aos das fêmeas devido a terem apresentado um melhor desempenho produtivo.

De acordo com a análise de regressão dos índices relativos de rentabilidade em função dos diferentes níveis de açafrão na dieta, houve um efeito quadrático com o ponto de mínima da curva de $8,4 \mathrm{~g} / \mathrm{kg}$, representando o nível com o pior índice relativo de rentabilidade (Figura 1). 
Figura 1. Efeito dos níveis de açafrão em pó na ração sobre o índice relativo de rentabilidade de frangos de corte no período de 1 a 42 dias de idade

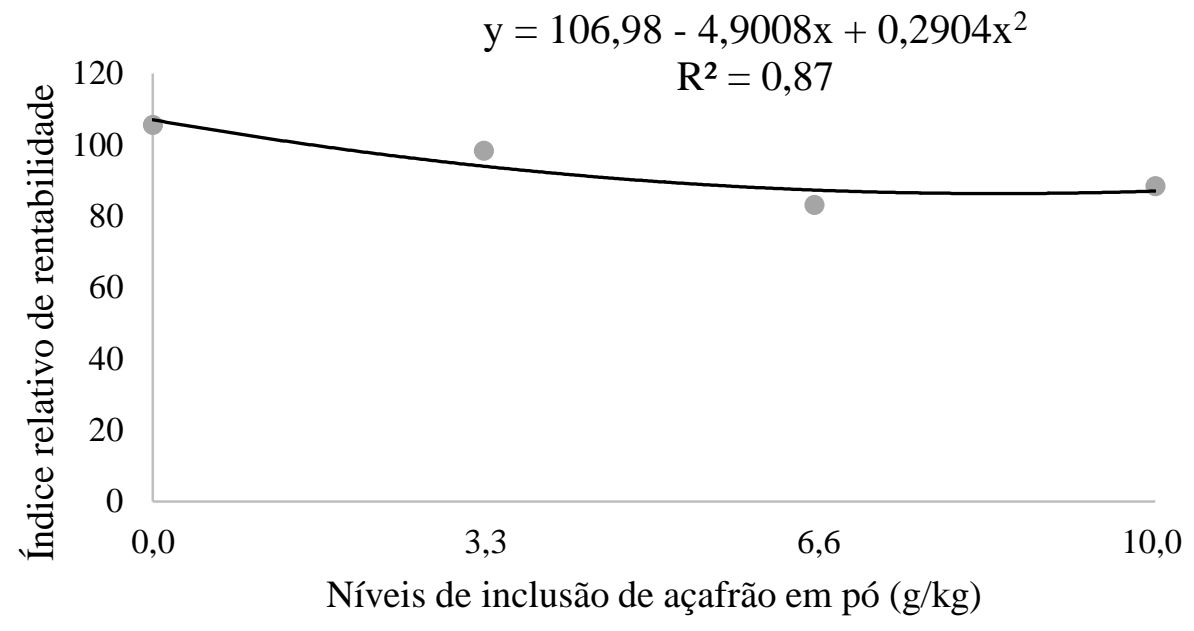

Resultados semelhantes foram verificados por Botelho (2014), que ao analisar a viabilidade econômica da inclusão de $0 ; 5 ; 10 ; 15$ e $20 \mathrm{~g} / \mathrm{kg}$ de açafrão na ração de frangos de corte, observou que à medida que houve aumento da inclusão de açafrão ocorreu uma redução linear no lucro, devido ao fato do açafrão não ter promovido efeito sobre desempenho e rendimento de carcaça das aves.

Entretanto, Durrani et al. (2006) observou em seu trabalho que o custo dos alimentos/kg de ganho de peso foi altamente favorável quando se adicionou $5 \mathrm{~g} / \mathrm{kg}$ de açafrão na ração de frangos em comparação aos demais níveis $(0 ; 2,5$ e $10 \mathrm{~g} / \mathrm{kg})$, indicando a viabilidade econômica do uso de açafrão como antifúngico e antioxidante neste nível.

De acordo com Santos (2010) o uso de alguns aditivos alternativos na dieta de frangos de corte aumenta o custo de produção, porém esse efeito pode ser minimizado pela agregação de valor ao frango produzido sem a adição de antibióticos promotores de crescimento.

\section{CONCLUSÕES}

A suplementação de açafrão em pó na ração de frangos de corte tem efeito semelhante ao antibiótico promotor de crescimento sobre o desempenho produtivo, rendimento de carcaça e de cortes nobres, peso relativo de vísceras e comprimento de intestinos das aves, sendo que o nível $3,3 \mathrm{~g} / \mathrm{kg}$ de açafrão possui a melhor rentabilidade econômica. Ainda são necessários maiores estudos sobre o modo de ação do açafrão sobre o metabolismo das aves.

\section{AGRADECIMENTOS}

Ao IF Goiano - Campus Ceres pelo financiamento da pesquisa e concessão da bolsa PIBITI/IF Goiano e à empresa "Neo Tec" pela doação do açafrão.

\section{REFERÊNCIAS BIBLIOGRÁFICAS}

ABBAS, R.Z.; IQBAL, Z.; KHAN, M.N.; ZAFAR, M.A.; ZIA, M.A. Anticoccidial activity of Curcuma longa L. in broilers. Brazilian Archives of Biology and Technology, v.53, n.1, p.63-67, 2010. https://doi.org/10.1590/S151689132010000100008

ABOU-ELKHAIR, R.; AHMED, H.A.; SELIM, S. Effects of black pepper (Piper nigrum), turmeric powder (Curcuma longa) and coriander seeds (Coriandrum sativum) and their combinations as feed additives on growth performance, carcass traits, some blood parameters and humoral immune response of broiler chickens. AsianAustralasian Journal of Animal Sciences, v.27, n.6, p.847-854, 2014. https://doi.org/10.5713/ajas.2013.13644

AL-SULTAN, S.I. The effect of Curcuma longa (Turmeric) on overall performance of broiler chicken. International Journal of Poultry Science, v.2, n.5, p.351-353, 2003. https://doi.org/10.3923/ijps.2003.351.353

BOTELHO, L.F.R. Açafrão (Curcuma longa L.) em rações para frangos de corte contendo sorgo em substituição ao milho. 2014. 39 f. Dissertação 
(Mestrado) - Programa de Pós-Graduação em Zootecnia, Universidade Estadual de Montes Claros, Janaúba, 2014.

CECILIO FILHO, A.B.; SOUZA, R.J.; BRAZ, L.R.; TAVARES, M. Curcuma: planta medicinal, condimentar e de outros usos potenciais. Ciência Rural, v.30, n.1, p.171-175, 2000. https://doi.org/10.1590/S0103$\underline{84782000000100028}$

CHENG, H.; LIU, W.; Al, X. Protective effect of curcumin on myocardial ischemia reperfusion injury in rats. Zhongyaocai Journal of Chinese medicinal materials, v.28, n.10, p.920-922, 2005.

DONO, N.D. Turmeric (Curcuma longa Linn.) supplementation as an alternative to antibiotics in poultry diets. Wartazoa, v.23, n.1, p.41-49, 2013.

DURRANI, F.R.; ISMAIL, M.; SULTAN, A.; DURRANI, Z. Effect of different levels of feed added turmeric (Curcuma longa) on the performance of broiler chicks. Journal of Agricultural and Biological Science, v.1, n.2, p.911, 2006.

EMADI, M.; KERMANSHASHI, H. Effect of turmeric rhizome powder on performance and carcass characteristics of broiler chickens. International Journal of Poultry Science, v.5, n.11, p.10691072, 2006.

https://doi.org/10.3923/ijps.2006.1069.1072

HUSSEIN, S.N. Effect of turmeric (Curcuma longa) powder on growth performance, carcass traits, meat quality, and serum biochemical parameters in broilers. Journal of Advanced Biomedical \& Pathobiology Research. v.3, n.2, p.25-32, 2013.

KUMARI, P.; GUPTA, M.K.; RANJAN, R.; SINGH, K.K.; YADAVA, R. Curcuma longa as feed additive in broiler birds and its patho-physiological effects. Indian Journal of Experimental Biology, v.45, p.272-277, 2007.

MEHALA, C.; MOORTHY, M. Effect of Aloe vera and Curcuma longa (turmeric) on carcass characteristics and biochemical parameters of broilers. International Journal of Poultry Science, v.7, n.9, p.865-861, 2008.
MONDAL, M.A.; YEASMIN, T.; KARIM, R.; SIDDIKY, M.N.A. Effect of dietary supplementation of turmeric (Curcuma longa) powder on the growth performance and carcass traits of broiler chicks. SAARC Journal of Agriculture, v.13, n.1, p.188199, 2015.

https://doi.org/10.3329/sja.v13i1.24191

NOUZARIAN, R.; TABEIDIAN, S.A.; TOGHYANI, M.; GHALAMKARI, G. Effect of turmeric powder on performance, carcass traits, humoral immune responses, and serum metabolites in broiler chickens. Journal of Animal and Feed Sciences, v.20, p.389-400, 2011. https://doi.org/10.22358/jafs/66194/2011

PINTÃO, A.M.; SILVA, I.F. A verdade sobre o açafrão. In: WORKSHOP PLANTAS MEDICINAIS E FITOTERAPÊUTICAS NOS TRÓPICOS. II CTT/CCM. Anais... out. 2008.

RAMOS, K.C.B.T.; GOMES, A.V.C.; LIMA, C.A.; CAMARGO, A.M.; CURVELLO, F.A.; SILVA, R.V.M.M.; MASSI, P.A. Desempenho produtivo e econômico de frangos de corte submetidos a programas de restrição alimentar. Ciência Animal Brasileira, v.12, n.1, p.8-16, 2011.

REDDY, P.; LOKESH, B.R. Effect of dietary turmeric (Curcuma longa) on iron-induced lipid peroxidation in the rat liver. Food and Chemical Toxicology, v.32, n.3, p.279-283, 1994. https://doi.org/10.1016/0278-6915(94)90201-1

ROSTAGNO, H.S.; ALBINO, L.F.T.; DONZELE, J.L.; GOMES, P.C.; OLIVEIRA, R.F.; LOPES, D.C.; FERREIRA, A.S.; BARRETO, S.L.T.; EUCLIDES, R.F. Tabelas brasileiras para aves e suínos: composição de alimentos e exigências nutricionais. 3. ed. Viçosa: UFV, 2011. 252 p.

SADEGHI, G.H.; KARIMI, A.; PADIDAR-JAHRONI, S.H.; AZIZI, T.; NAESHMAND, A. Effects of cinnamon, thyme and turmeric infusions on the performance and immune response in of 1- to 21day-old male broilers. Brazilian Journal of Poultry Science, v.16, n.1, p.15-20, 2012. https://doi.org/10.1590/S1516$\underline{635 \times 2012000100003}$

SAMARASINGHE, K.; WENK, C.; SILVA, K.F.S.T.; GUNASEKERA, J.M.D.M. Turmeric (Curcuma longa) root powder and mannanoligosaccharides as alternatives to antibiotics in broiler chicken 
diet. Asian-Australasian Journal of Animal Sciences, v.16, n.10, p.1495-1500, 2003. https://doi.org/10.5713/ajas.2003.1495

SANTOS, G.C. Alternativas ao uso de promotores químicos de crescimento sobre o desempenho e características de carcaça de frangos de corte. 2010. 67 p. Monografia (Trabalho de Conclusão de Curso de Graduação em Zootecnia) Faculdade de Ciências Agrárias, Universidade Federal dos Vales do Jequitinhonha e Mucuri, Diamantina, 2010.

SILVA, F.A.S. Assistat Versão $\mathbf{7 . 7}$ beta. Campina Grande: Universidade Federal de Campina Grande, 2016.

SUGIHARTO, I.; WIDIASTUTI, E.; PRABAWO, N.S. Effect of turmeric extract on blood parameters, feed efficiency and abdominal fat content in broilers. Journal of the Indonesian Tropical Animal Agriculture, v.36, n.1, p.21-26, 2011. https://doi.org/10.14710/jitaa.36.1.21-26

VILELA, C.A.A.; ARTUR, P.O. Secagem do açafrão (Curcuma longa L.) em diferentes cortes geométricos. Ciência e Tecnologia de Alimentos, v.28, n.2, p.327-394, 2008. https://doi.org/10.1590/S0101-

20612008000200018

WANG, D.; HUANG, H.; ZHOU, L.; LI, W.; ZHOU, H.; HOU, G.; LIU, J.; HU, L. Effect of dietary supplementation with turmeric rhizome extract on growth performance, carcass characteristics, antioxidant capability, and meat quality of Wenchang broiler chickens. Italian Journal of Animal Science, v.14, p.344-349, 2015. https://doi.org/10.4081/ijas.2015.3870

YARRU, L.P.; SETTIVARI, R.S.; GOWDA, N.K.; ANTONIOU, E.; LEDOUX, D.R.; ROTTINGHAUS, G.E. Effects of turmeric (Curcuma longa) on the expression of hepatic genes associated with biotransformation, antioxidant, and immune systems in broiler chicks fed aflatoxin. Poultry Science, v.88, n.12, p.2620-2627, 2009. https://doi.org/10.3382/ps.2009-00204
Recebido para publicação em 16/08/2017

Revisado em 13/09/2017

Aceito em 09/10/2017 